九州大学学術情報リポジトリ

Kyushu University Institutional Repository

A Field Study of Water Lead Pollution in Fresh Water Areas of Northern Kyushu, based on 5Aminolevulinic Acid Dehydratase Activity and Lead Concentration in the Blood of Crucian Carp, Carassius auratus langsdorfii

Nakagawa, Hisaki

Laboratory of Fisheries Chemistry, Faculty of Agriculture, Kyushu University

Tajima, Toshihiro

Laboratory of Fisheries Chemistry, Faculty of Agriculture, Kyushu University

Sato, Tsutomu

Laboratory of Fisheries Chemistry, Faculty of Agriculture, Kyushu University

Kuboyama, Midori

The Center of Advanced Instrumental Analysis, Kyushu University

https://doi.org/10.5109/24266

出版情報：九州大学大学院農学研究院紀要. 43 (1/2)，pp. 209-215，1998-11. Kyushu University バージョン：

権利関係: 


\title{
A Field Study of Water Lead Pollution in Fresh Water Areas of Northern Kyushu, based on 5-Aminolevulinic Acid Dehydratase Activity and Lead Concentration in the Blood of Crucian Carp, Carassius auratus langsdorfii
}

\author{
Hisaki Nakagawa, Toshihiro Tajima, Tsutomu Sato \\ and Midori Kuboyama* \\ Laboratory of Fisheries Chemistry, Faculty of Agriculture, Kyushu University, \\ Fukuoka 812-8581, Japan \\ (Receined July 29, 1998 and accepted August 7, 1998)
}

\begin{abstract}
The enzyme 5-aminolevulinic acid dehydratase (ALA-D) in the blood of crucian carp Carassius auratus langsdorfizi is useful as an indicator of water lead pollution. The actual conditions of water lead pollution in fresh water areas of northern Kyushu were investigated using ALA-D activity and lead concentration in fish blood between Aug. and Oct., 1996. The results obtained were as follows. Blood ALA-D activity in the collected fish varied both within any one sampling location and among the various sampling locations. But, from the mutual comparison of blood $\mathrm{ALA}-\mathrm{L}$ ) activities of crucian carp collected at various sampling locations, no significant differences were observed between them. Blood lead concentrations in the collected fish suggested that water lead concentrations had changed to a slight degree over time at the various sampling locations prior to our field study. A comparison between the data of our field study and those of the exposure test, reported in our previous paper using $A I_{A} A-D$ ) activity and lead concentration of crucian carp blood, seemed to demonstrate that water lead concentrations in all the sampling locations were below the water quality slandard for water lead (10 ppb).
\end{abstract}

\section{INTRODUCTION}

The enzyme 5-aminolevulinic acid dehydratase (ALA-D, EC 4.2.1.24) in fish blood is useful as an indicator of water lead poliution because ALA-D activity is especially inhibited by lead contamination (Hodson, 1976; Hodson et al., 1977; Johansson-Sjöbeck and Larsson, 1979; Schmitt et al., 1984; Larsson et al., 1985; Haux et al., 1986; Dwyer et al., 1988; Nakagawa et al., 1995a; Nakagawa et al., 1995b; Nakagawa et al., 1995c; Nakagawa et al., 1995d; Nakagawa et al., 1997a; Nakagawa et al., 1997b). In addition, fish blood ALA-I) is useful as an indicator of lead pollution because of the following characteristics: 1) The ALA-D activity reflects the degree of lead contamination that fish have suffered in the past. 2) The inhibition of ALA-D activity is induced by short-term lead exposure. 3) The depressed ALA-D activity recovers slowly. These characteristics mean that blood ALA-D is also useful for diagnosing past exposure to lead, even if lead in the water at the time of analysis is of the usual background concentration (Hodson et al, 1977; Nakagawa et al., 1995a). Crucian carp, Carassius auratus langsdorfiz lives extensively in fresh water areas, such as the rivers and lakes etc., of northern Kyushu. The fish can be collected easily by a fishing rod. It has also been verified previously that

\footnotetext{
* The Center of Advanced Instrumental Analysis, Kyushu University, Fukuoka 812-8581, Japan
} 
the blood ALA-D activity of crucian carp is suitable as an indicator of water lead pollution by means of a lead exposure test (Nakagawa et al., 1997a).

We performed a field study in order to assess the actual conditions of water lead pollution in the fresh water areas of northern Kyushu using ALA-D activity and lead concentration in crucian carp blood, and the results obtained are presented here.

\section{MATERIALS AND METHODS}

\section{Sampling locations}

Sampling locations in fresh water areas of northern Kyushu are shown in Fig. 1. The field study was performed at Chikugo-oozeki along the Chikugo river, at Onga bridge (in Nakama city) along the Onga river, at Yoshihara bridge and Katamine bridge along the Umi river, at Nagatani dam in Fukuoka city, and at Onizuka where the Matsuura river joins the Tokusue river in Saga prefecture, between Aug. and Oct., 1996.

\section{Collection method and treatment after collection}

Crucian carp were collected by a fishuing rod at the sampling locations. Stress, such as collection, transport, and the handling of the fish was thought to induce increased ALA-D activity and therefore the collected fish were carried carefully to the laboratory with aerating. The fish were then kept in a water tank at the laboratory for 2 to 4 days to allow them to recover from the stress, according to the recommendation of Larsson et al. (1985).

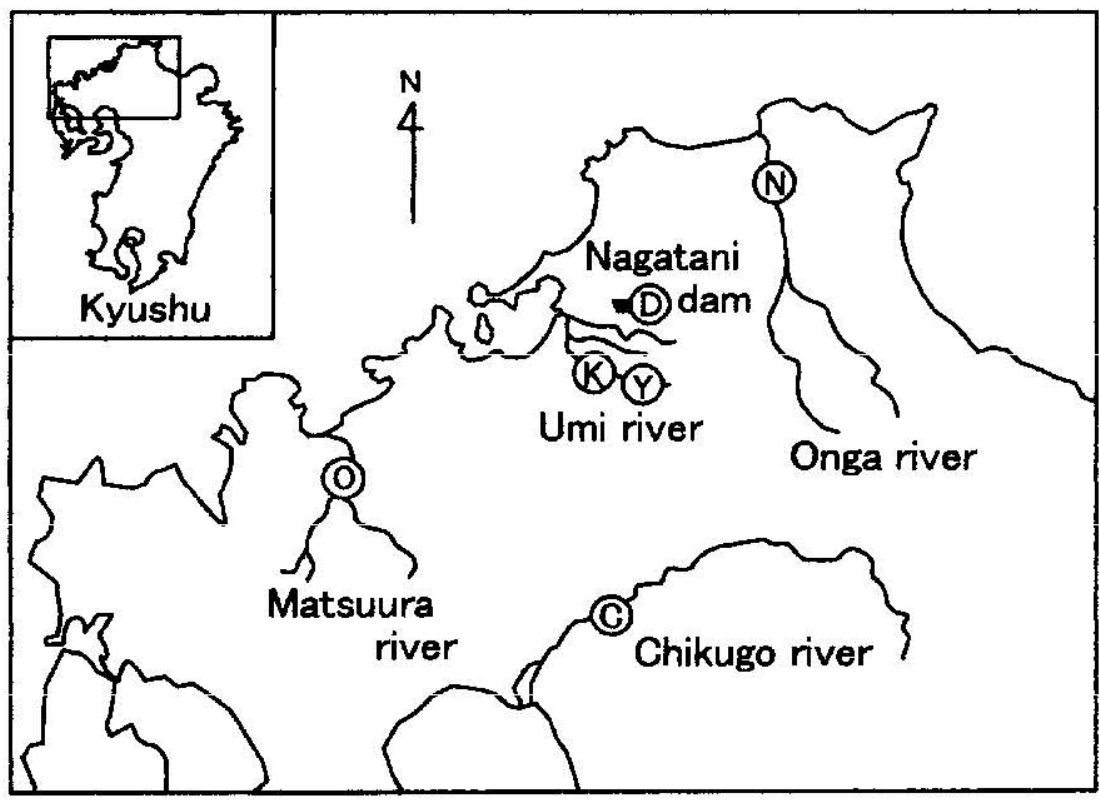

Fig. 1. Sampling locations in fresh water areas of northern Kyushu. Sampling locations comprised Chikugo-oozeki $(\mathbb{C}$ ), Onga bridge $(\mathbb{N}$, Yoshihara bridge $(\underline{Y}$, Katamine bridge (K, Nagatani dam (D) and Onizuka (0). 


\section{Measurement of blood ALA-D activity}

ALA-D activity was measured by a modified method which does not use $\mathrm{HgCl}_{2}$, as described in our previous report (Nakagawa et al., 1995b). The activity was expressed as nmol of porphobilinogen (PBG) which was formed from aminolevulinic acid by $1 \mathrm{ml}$ of erythrocyte ( $\mathrm{RBC}$ ) for $1 \mathrm{~h}(\mathrm{nmol} \mathrm{PBG} / \mathrm{ml} \mathrm{RBC} / \mathrm{h})$, according to the formula of Hodson et al. (1977). In addition, blood collection from fish and measurement of the hematocrit value (Hct) also followed the methods previously reported (Nakagawa et al., 1995a).

\section{Measurement of blood lead concentration}

Blood lead concentration was measured according to our previous report (Nakagawa et al., 1995a).

\section{Method for Certifying Actual Conditions of Lead Pollution in Water of Sampling Locations}

Verification of whether or not the water of the sampling locations had been polluted by water lead was carried out as follows. Firstly, ALA-D activities and lead concentrations in the blood of collected crucian carp were compared according to the sampling location, and significant differences were evaluated. Furthermore, data regarding the ALA-D activities and lead concentrations in the fish blood from the field study were compared with those from a lead exposure test reported in our previous paper (Nakagawa et $a l ., 1997 \mathrm{a}$ ). A judgement was thus made as to whether or not the water of the sampling locations had been polluted by water lead.

Data were analyzed for statistical significance by the Student's $t$-test and significant differences were established at the $5 \%$ level.

\section{RESULTS AND DISCUSSION}

Body length, body weight, condition factor, Hct, blood ALA-D activities, and blood lead concentrations of crucian carp collected at sampling locations are shown in Table 1.

\section{Relationships of blood ALA-D activities and blood lead concentrations to body length, body weight, condition factor and Het}

The mean body length and body weight of the collected fish varied from $14.6-19.1 \mathrm{~cm}$ and from 94.7-233.5g, respectively. The mean condition factor [(body weight)/(body length) $\times 1000$ ], varied from $28.8-30.7$. In addition, the mean Hct value varied from 28.1 to $33.7 \%$. It was thought that the age and state of nutrition of the collected fish differed to a degree among the various sampling locations according to these measurements. As regards the variables of all crucian carp collected at sampling locations, the relationships between blood ALA-D activities and blood lead concentrations, the relationships between ALA-D activities and the four variables of body length, body weight, condition factor and Hct and the relationships between lead concentrations and the same four variables were all examined. The results obtained were as follows. The ALA-D activities were negatively but only slightly correlated to the lead concentrations ( $\mathrm{r}=-0.25)$. The ALA-D activities were negatively and minimally correlated to body length $(r=-0.23)$ and body weight $(r=-0.24)$, but no correlation of ALA-D activities to condition factor or Hct was obtained. 
Table 1. Sample number, body variables, hematocrit, blood ALA-D) activities and blood lead levels of crucian carp collected at various sampling locations within fresh water areas of northern Kyushu between Aug. and Oct., 1996

\begin{tabular}{|c|c|c|c|c|c|c|}
\hline & \multicolumn{6}{|c|}{ Sampling location } \\
\hline & Chikugo-oozeki & Onga bridge & Yoshihara bridge & Katamine bridge & Nagatani dam & Onizuka \\
\hline Sarnple number & 10 & 6 & 8 & 11 & 7 & 7 \\
\hline Body length $(\mathrm{cm})$ & $18.2+1.4^{+i}$ & $19.1=3 . \overline{7}$ & $15.5 \pm 2.5$ & $14.6 \pm 3.3$ & $j 7.4 \pm 2.4$ & $17.8 \pm 2.2$ \\
\hline Body weight (g) & $177.7 \pm 32.0^{\circ}$ & $233.5 \pm 139.2$ & $119.9=56.7$ & $94.7 \pm 56.8$ & $157.9=70.3$ & $175.0 \pm 57.5$ \\
\hline Condition factor & $29.5 \pm 2.4^{\prime 1}$ & $30.4 \pm 1.2$ & $30.7 \pm 1.5$ & $28.8 \pm 4.8$ & $28.8 \pm 1.7$ & $30.0 \pm 3.0$ \\
\hline Hemalocrit $(\%)$ & $33.7 \pm 4.9^{\circ}$ & $32.3 \pm 3.2$ & $33.1 \pm 2.8$ & $28.1 \pm 5.0$ & $30.3 \pm 4.7$ & $31.2 \pm 8.8$ \\
\hline \multicolumn{7}{|l|}{ ALA-D activity } \\
\hline (IInol PBG/rn RBC/h) & h) $582.0 \pm 97.0^{x_{1}=}$ & $702.7 \pm 3555.5$ & $617.4 \pm 171.7^{* 2}$ & $538.7 \pm 126.7^{\cdots+3}$ & $630.7 \pm 136.0=$ & $649.8 \pm 259.6$ \\
\hline Blood Pb level (ppb) & $72.4 \pm 24.8^{*}$ & $50.4 \pm 16.6$ & $84.2 \pm 25.2^{2=5}$ & $73.9 \pm 14.6^{6.4 i}$ & $61.8 \pm 13.1$ & $61.2 \pm 10.3$ \\
\hline
\end{tabular}

*1 Results are expressed as mean \pm SD.

*2 Mean value of the fish collected in field survey was not significantly different from that of the fish collected at Onga bridge along the Onga river at $5 \%$ level.

*3 Mean value was significantly different, from that of the control fish of the lead exposure test in Table 2 at $5 \%$ level.

*4 Mean value was not significantly different from that of the fish exposed to $3 \mathrm{ppb}$ of lead concentration in Table 2 at $5 \%$ level.

*5 Mean value was significantly different from that of the fish collected at Onga bridge along the Onga river at $5 \%$ level.

*6 Mean value was not significantly different from that of the control fish of the lead exposure 1.est in Table 2 at $5 \%$ level.

In addition, no correlation of the lead concentrations to the four variables was obtained.

\section{Variations in blood ALA-D activities within any one sampling location and among various sampling locations}

The mean values of blood ALA-D activity of the collected fish varied from 538.7-702.7 nmol PBG/mi RBC/h. Biood ALA-D activities were different for every fish within each sampling location. The highest mean value of blood ALA-D activity was observed in the fish collected at Onga bridge along the Onga river when compared with those collected at the other sampling locations. Therefore, the values of the mean and standard deviation of blood ALA-D activities in the fish collected at Onga bridge were compared with those in the fish collected at the other sampling locations, but no significant differences were observed. It was thought that the variation in blood ALA-D activity simply reflected differences among individual crucian carp collected at the various sampling locations in the present field study.

\section{Variations in blood lead concentrations within any one sampling location and among various sampling locations}

The mean values of blood lead concentration in the collected fish varied from 50.4-84.2 ppb. Blood lead concentrations were different for every fish within each 
sampling location. The lowest mean value of blood lead was observed in the fish collected at Onga bridge along the Onga river, when compared with those collected at the other sampling locations. Therefore, this lowest mean value of blood lead was compared with those of other sampling locations. It was found that the lowest mean value was significantly different from those in the fish collected at both Katamine bridge and Yoshihara bridge along the Umi river. The next lowest mean value of blood lead was observed in the fish collected at Onizuka along the Matsuura river. This mean value of blood lead was also compared with those of the other sampling locations, but no significant differences were observed. From the mutual comparison of blood lead concentrations of crucian carp collected at various sampling locations, it was thought that water lead concentrations in the water of the sampling locations had changed to a slight degree over time prior to our field study.

\section{Actual conditions of water lead pollution in fresh water areas of northern Kyushu}

Table 2 shows the values of ALA-D activity and lead concentration in crucian carp blood on the basis of data reported in our previous paper regarding a three-week exposure test of fish to water lead (Nakagawa et al., 1997a). With regard to ALA-D activities and lead concentrations in the fish blood, the data from the field study reported in Table 1 were compared with those from the exposure test reported in Table 2, in order to verify whether or not water of the sampling locations had been polluted by water lead. The results obtained were as follows. As regards blood ALA-I) activity, the values of the fish exposed to control water were compared with those of the fish collected at various sampling locations. It was noted that the value of the control fish was significantly different from that of the fish collected at Katamine bridge along the Umi river among the various sampling locations. However, the value of the fish exposed to water lead of $3 \mathrm{ppb}$ was not significantly different from that of the fish collected at Katamine bridge. As regards blood lead concentration, the value of the fish exposed to control water was compared with those of the fish collected at the various sampling locations, but no significant difference was found.

The present value of the water quality standard for water lead in Japan is $10 \mathrm{ppb}$. From the results of the comparison made between the data of the field study indicated in

Table 2. ALA-D activities and lead levels in the blood of crucian carp exposed for 3 weeks to water lead of 3,10 , and $30 \mathrm{ppb}$ and to control water

\begin{tabular}{lcccc}
\hline & \multicolumn{4}{c}{ Nominal lead concentration (ppb) } \\
\cline { 2 - 5 } & Control $(0.45)$ & 3 & 10 & 30 \\
\hline ALA-D activity & & & & \\
(nnol PBG/rnd RBC/h) & $670.0 \pm 122.0^{\circ}$ & $578.5+100.6$ & $474.0 \pm 76.2$ & $290.8+81.9$ \\
Blood Pb level (ppb) & $62.1 \pm 19.1^{\wedge}$ & $148.5 \pm 21.7$ & $267.4 \pm 31.0$ & $800.5 \pm 218.5$ \\
\hline
\end{tabular}

*1 Results are expressed as mean \pm SD of seven fish. These values are quoted and reformed from the data of a rcported proviously paper (Nakagawa et al., 1997a) 
Table 1 and the data of the exposure test reported in Table 2, based on ALA-D activities and lead concentrations of crucian carp blood, lead concentrations of the fresh water areas investigated in the present field study were below the water quality standard for water lead, and it could thus be concluded that water lead pollution had not occurred at our sampling locations.

As indicated in Table 1, values of blood ALA-D activity of crucian carp collected in the present field study varied largely within any one sampling location and among various sampling locations. On the other hand, variations in values of blood ALA-D activities of the fish used in the exposure test was small, as indicated in Table 2. Fish of a similar size from the same living water areas were used as test fish. Therefore, it is thought that the variations in values of blood ALA-D activities of the test fish were smaller in comparison to variations in those of the fish collected in the field study. If there are water areas where water lead pollution is suspected, it is possible to ascertain the source of lead pollution by measuring ALA-D activity in the fish caged in the suspected water areas. From the characteristic that depressed ALA-D activity recovers slowly, fish blood ALA-D is useful for diagnosing past exposure to lead, even if lead in the water at the time of analysis is of an acceptable background concentration. Carp, Cyprinus carpio is used frequently as test fish of a exposure test, and can be purchased easily from an aquarium supplier. It has also been verified previously that the blood ALA-D activity of carp is suitable as an indicator of water lead pollution by means of a lead exposure test (Nakagawa et al., 1995abd). In Japanese fresh water areas, carp is one of the most suitable fish with which to ascertain the source of lead pollution by measuring blood ALA-D activity in the fish caged in the suspected water areas.

\section{ACKNOWLEDGMENTS}

The English used in this manuscript was revised by Miss K. Miller (Royal English Language Centre, Fukuoka, Japan). This study was supported in part by a Grant-in-Aid for Scientific Research from the Ministry of Education, Science and Culture of Japan (No. 06680510).

\section{REFERENCES}

Dwyer, F. J., C. J. Schunitt, S. E. Finger, and P. M. Mchrle 1988 Biochemical changes in longear sunfish Lepomis megalotis associated with lead, cadmium and zinc from mine tailings. J. Fish Biol., 33: $307-317$

Haux, C., Ă. Larsson, G. Lithner, and M.-L. Sjöbeck 1986 A field study of physiological effects on fish in lead-contaminated takes. Eriviron. Toxicol Chem., 5: 283-288

Hodson, P. V. $1976 \quad \delta$-Aminolevulinic acid dehydratase activity of fish blood as an indicator of a harmful exposure to lead. J. Fish. Res. Bd. Can., 33: 268-271

Hodson, P. V., B. R. Blunt, D. J. Spry, and K. Austen 1977 Evaluation of crythrocytc $\delta$-aminolevulinic acid dehydratase activity as a short term indicator in fish of a harmful exposure to lead. $J$. Fish. Res. Bd. Can., 34: $501-508$

Johansson-Sjöbeck, M. L. and $\AA$. Larsson 1979 Effects of inorganic lead on delta-aminolevulinic acid dehydratase activity and hematological variables in the rainbow trout Salmo gairdneri. Arch. Environ. Contam. Toxicol., 8: 419-431

Larsson, Å., C. Haux, and M.-L. Sjöbeck 1985 Fish physiology and metal pollution: Results and expericnces from laboratory and field studies. Evotoxicol. Environ. Saf., 9: 250-281 
Nakagawa, H., K. Nakagawa, and T. Sato 1995a. Evaluation of erythrocyle 5-aminolevulinic acid dehydratase activity in the blood of carp Cyprinus carpio as an indicator in fish of water lead pollution. Fisheries Sci., 61: 91-95

Nakagawa, H., T. Sato, and H. Kubo $1995 \mathrm{~b}$ Method not requiring mercuric chloride for the determination of activity of 5-aminolevulinic acid delydratase in blood of carp Coprinus owrpio. Fisheries Sci., 61: $97-99$

Nakagawa, K., H. Nakagawa, and Y. Aso 1995c The type of inhibition of erythrocyte 5-aminolevulinic acid dehydratase in the blood of carp Cyprinus carpio caused by lead and cadmium. Sci. Bull. Fac. Agr., Kyushu Lniv., 50: 51-57 (in Japanese with English summary)

Nakagawa, H., T. Sato, and H. Kubo 1995d Evaluation of chronic toxicity of water lead for carp Cyprinus carpio using its blood 5-aminolevulinic acid dehydratase. Fisheries Sci., 61: 956-959

Nakagawa, H., T. Tajima, T. Sato, and M. Watanabe 1997 a Evaluation of erythrocyte 5-aminolevulinic acid dehydratase activity in the blood of crucian carp Carassius auratus langsaorfii as an indicator in fish of water lead pollution. J. Fac. Agr., Kyushu Lniw., 41: 205-213

Vakagawa, H., R. Matsuo, T. Sato, and M. Watanabe 1997b Storage niethod for blood that provides stability of erythrocyte 5-aminolevulinic acid dehydratase of carp Cyprinus carpio when used as an indicator of water lead pollution. J. Fac. Agr., Kyushu Univ, 41:215-221

Schmitt, C. J., F. J. Dwyer, and S. E. Finger 1984 Bioavailability of $\mathrm{Pb}$ and $\mathrm{Zn}$ from mine tailings as indicated by erythrocyte $\delta$-aminolevulinic acid dehydratase (ALA-D) activity in suckers (Pisces: Catostomidae). Can. J. Fish Aquat. Sci, 41: 1030-1040 